\title{
Bronchodilator response of advanced lung function parameters depending on COPD severity
}

International Journal of COPD

25 November 2016

Number of times this article has been viewed

\section{Linnea Jarenbäck' \\ Göran Eriksson' \\ Stefan Peterson ${ }^{2}$ \\ Jaro Ankerst' \\ Leif Bjermer' \\ Ellen Tufvesson'}

'Respiratory Medicine and Allergology, Department of Clinical Sciences Lund, Lund University, ${ }^{2}$ Regional Cancer

Center South, Skåne University

Hospital, Lund, Sweden
Correspondence: Linnea Jarenbäck Respiratory Medicine and Allergology, Department of Clinical Sciences Lund, BMC, DI2, Lund University,

22I 84 Lund, Sweden

$\mathrm{Tel}+46462227828$

Email linnea.jarenback@med.lu.se
Background: COPD is defined as partly irreversible airflow obstruction. The response pattern of bronchodilators has not been followed in advanced lung function parameters.

Purpose: The aim of this study was to investigate bronchodilator response pattern in advanced lung function parameters in a continuous fashion along forced expiratory volume in 1 second $\left(\mathrm{FEV}_{1}\right)$ percent predicted $(\% \mathrm{p})$ in COPD patients and controls.

Patients and methods: Eighty-one smokers/ex-smokers (41 controls and 40 COPD) performed spirometry, body plethysmography, impulse oscillometry and single-breath helium dilution carbon monoxide diffusion at baseline, after salbutamol inhalation and then after an additional inhalation of ipratropium.

Results: Most pulmonary function parameters showed a linear increase in response to decreased $\mathrm{FEV}_{1} \% \mathrm{p}$. The subjects were divided into groups of $\mathrm{FEV}_{1} \% \mathrm{p}<65$ and $>65$, and the findings from continuous analysis were verified. The exceptions to this linear response were inspiratory capacity (IC), forced vital capacity (FVC), $\mathrm{FEV}_{1} / \mathrm{FVC}$ and expiratory resistance $\left(R_{\mathrm{ex}}\right)$, which showed a segmented response relationship to $\mathrm{FEV}_{1} \% \mathrm{p}$. IC and $\mathrm{FVC}$, with break points (BP) of 57 and $58 \mathrm{FEV}_{1} \%$ p respectively, showed no response above, but an incresed slope below the $\mathrm{BP}$. In addition, in patients with $\mathrm{FEV}_{1} \% \mathrm{p}<65$ and $>65$, response of $\mathrm{FEV}_{1} \% \mathrm{p}$ did not correlate to response of volume parameters.

Conclusion: Response of several advanced lung function parameters differs depending on patients' baseline $\mathrm{FEV}_{1} \% \mathrm{p}$, and specifically response of volume parameters is most pronounced in COPD patients with $\mathrm{FEV}_{1} \% \mathrm{p}<65$. Volume and resistance responses do not follow the flow response measured with $\mathrm{FEV}_{1}$ and may thus be used as a complement to $\mathrm{FEV}_{1}$ reversibility to identify flow, volume and resistance responders.

Keywords: COPD, IOS, body plethysmography, bronchodilation, lung function, reversibility

\section{Introduction}

COPD is one of the world's leading causes of death and is defined to have a progressive, partly irreversible airflow limitation due to a chronic inflammation in the airways. It is heterogenic in nature with varying degrees of emphysema and chronic bronchitis. COPD is diagnosed in patients using anamnesis and spirometry, but it is known that flow-volume spirometry mainly measures alterations in the central airways. Recently, it has been observed that destruction in the peripheral airways is present prior to changes observed by spirometry, ${ }^{1}$ and methods to measure the peripheral airway changes are necessary. We have previously shown that baseline impulse oscillometry (IOS) parameters seem to be more affected in moderate-to-severe COPD patients, while volume and diffusion parameters are more affected in severe and very severe COPD patients. In addition, we showed that the lung function parameters are widely spread in Global Initiative for chronic Obstructive Lung Disease (GOLD) stage 2. ${ }^{2}$ Post hoc 
investigations of this study identified break points (BPs) in the linear relationship between forced expiratory volume in 1 second $\left(\mathrm{FEV}_{1}\right)$ percent predicted $(\% \mathrm{p})$ and advanced lung function parameters, identifying a change in the lung function pattern when $\mathrm{FEV}_{1} \% \mathrm{p}$ drops below $65 .{ }^{3}$ However, how these patterns change due to bronchodilators is not known. The topic of whether the bronchodilator response in $\mathrm{FEV}_{1}$ is limited in COPD patients has been discussed, ${ }^{4}$ and studies have explored the reversibility of $\mathrm{FEV}_{1}$, forced vital capacity (FVC) and $\mathrm{FEV}_{1} / \mathrm{FVC}$ based on disease stage (based on GOLD stages). ${ }^{5,6}$ Other studies suggest that the reversibility of $\mathrm{FEV}_{1}$ is not a useful tool in COPD and that there might be many other relevant parameters when evaluating the response. ${ }^{4}$ In some studies, other advanced lung function parameters are used to evaluate the response, ${ }^{7-13}$ but there is no information about the clinically significant response and the parameters that are most effective to use. The use of volume parameters for assessing bronchodilator response in patients with hyperinflation has shown that bronchodilation decreases hyperinflation. ${ }^{14}$ The response of parameters of forced oscillometry (FOT) after salbutamol has recently been described in different GOLD stages. These data showed a significant response in milder stage of COPD compared to controls with a tendency of lower response in more advanced stage. ${ }^{15}$ However, the bronchodilator response of parameters measured by the closely related IOS method and volume parameters measured by body plethysmography in correlation to other parameters has not been investigated in relation to COPD disease severity based on $\mathrm{FEV}_{1} \%$ p.

We aimed to investigate the response of advanced lung function parameters, beyond $\mathrm{FEV}_{1}$, to short-acting bronchodilators in a continuous fashion over a broad range of $\mathrm{FEV}_{1} \% \mathrm{p}$. Hence, we identified the relevant parameters that are most important when assessing bronchodilator response and at which disease severity patients benefit most from the treatment.

\section{Patients and methods}

\section{Study participants}

A total of 81 volunteers (smokers and ex-smokers) were included in the study (Table 1) and were classified as controls (fixed ratio $\mathrm{FEV}_{1} / \mathrm{FVC}>0.7$; $=41$ ) or COPD patients $\left(\mathrm{FEV}_{1} / \mathrm{FVC}<0.7 ; \mathrm{n}=40\right)$. After the continuous analysis, subjects were also divided into $\mathrm{FEV}_{1} \% \mathrm{p}<65$ and $>65$ (independent of $\mathrm{FEV}_{1} / \mathrm{FVC}$ ) to assess subjects at different disease stages. This division was based on our previous study that indicates that the disease patterns change around $\mathrm{FEV}_{1} \% \mathrm{p}$ of $65 \%$ p. ${ }^{3}$ All study participants refrained from their inhaled bronchodilators 8 hours (short-acting $\beta 2$ agonist [SABA] or short-acting muscarinic antagonist [SAMA]) and
48 hours (long-acting $\beta 2$ agonist [LABA] or long-acting muscarinic antagonist [LAMA]), respectively, before the visit. All participants had $\geq 10$ pack-years and had no previous diagnoses of asthma or any other pulmonary disease (except COPD) or any lower respiratory infection/ exacerbation within the last 3 weeks.

\section{Study design}

Study participants performed IOS (MasterScreen, Erich Jaeger GmbH, Würzburg, Germany) giving information about total airway resistance (R5), central airway resistance (R20), peripheral airway resistance (R5-R20), reactance at $5 \mathrm{~Hz}$ (X5), reactance area (AX) and resonance frequency $\left(F_{\text {res }}\right) .{ }^{16}$ Body plethysmography with spirometry (MasterScreen Body, Erich Jaeger $\mathrm{GmbH})^{17}$ provided information about flow and volume parameters, $\mathrm{FEV}_{1}, \mathrm{FVC}, \mathrm{FEV}_{1} / \mathrm{FVC}$, functional residual capacity (FRC), residual volume (RV), inspiratory capacity (IC) and total lung capacity (TLC), and resistance, including inspiratory resistance $\left(R_{\mathrm{in}}\right)$ and expiratory resistance $\left(R_{\mathrm{ex}}\right)$. Single-breath helium dilution carbon monoxide diffusion (MasterScreen Diffusion, Erich Jaeger $\mathrm{GmbH})^{18-20}$ was performed to obtain diffusion capacity of the lung for carbon monoxide $\left(\mathrm{D}_{\mathrm{L}, \mathrm{CO}}\right)$, alveolar volume (VA), $\mathrm{D}_{\mathrm{L}, \mathrm{CO}} / \mathrm{VA}, \mathrm{RV}, \mathrm{FRC}$ and TLC. These measurements were performed at baseline, 10 minutes after inhalation of SABA (400 $\mu$ g salbutamol; Buventol ${ }^{\circledR}$, Easyhaler ${ }^{\circledR}$ ) and then again 40 minutes after inhalation of additional SAMA $\left(80 \mu \mathrm{g}\right.$ ipratropium; Atrovent ${ }^{\circledR}$, Handihaler $\left.^{\circledR}\right)$ (Figure 1). Lung function measurements were performed according to manufacturer's instructions and European Respiratory Society/American Thorax Society recommendations. ${ }^{19,21,22}$ The reference values used were established by Crapo et $\mathrm{a}^{23}$ (spirometry), Quanjer et $\mathrm{al}^{24}$ (body plethysmography and single breath) and $\operatorname{Vogel}^{25}$ (IOS). Study participants also filled the Clinical COPD Questionnaire.

This study was approved by the Regional Ethical Review Board in Lund (431/2008) and followed the guidelines set in the Declaration of Helsinki, and all study participants signed the informed consent.

\section{Statistics}

To detect BPs, a regression model allowing segmented relationships was performed as previously described. ${ }^{3}$ Shortly, this method estimates a new model having a segmented relationship from an existing linear regression (LR) model. ${ }^{3}$ Ordinary LR and a nonparametric fit by the loess (local regression) line are also used for visual purpose. ${ }^{26-28}$

Figure $2 \mathrm{~A}$ and $\mathrm{B}$ shows the $\mathrm{FVC} \% \mathrm{p}$ at baseline and after inhalation of SABA and additional SAMA, respectively, in 
Table I Patient characteristics, daily medication and baseline lung function

\begin{tabular}{|c|c|c|c|}
\hline & All & Group I $($ FEV $\%<65)$ & Group $2(F E V, \%>65)$ \\
\hline \multicolumn{4}{|l|}{ Demographics } \\
\hline $\mathrm{N}$ & 81 & 27 & 54 \\
\hline Age (range), years & $67(65-68)$ & $65(6 I-67)$ & $67(66-69)^{* *}$ \\
\hline Current/former smoker, $\mathrm{n}$ & $19 / 62$ & $4 / 23$ & $15 / 39$ \\
\hline Pack-years (range) & $30(23-40)$ & $38(28-50)$ & $27(21-37)^{* *}$ \\
\hline Sex, females/males & $39 / 42$ & $13 / 14$ & $26 / 28$ \\
\hline COPD, $\mathrm{n}$ & 40 & 27 & 13 \\
\hline BMI (range), $\mathrm{kg} / \mathrm{m}^{2}$ & $26(24-29)$ & $25(23-29)$ & 27 (24-29) \\
\hline ICS, $n$ & 22 & 17 & 5 \\
\hline SABA, $n$ & 13 & 11 & 2 \\
\hline LAMA, $\mathrm{n}$ & 24 & 18 & 6 \\
\hline LABA, $n$ & 21 & 17 & 4 \\
\hline CCQ score (range) & $6(2-14)$ & $14(8-2 \mid)$ & $4(2-7)^{* * *}$ \\
\hline \multicolumn{4}{|l|}{ Body plethysmography } \\
\hline $\mathrm{FEV}_{\text {, }}$ (range), L & $2.1(1.6-2.9)$ & I.I (I.0-I.8) & $2.6(2.1-3.2)^{* * *}$ \\
\hline $\mathrm{FEV}_{1}$ (range), \%p & $82(50-94)$ & $42(33-50)$ & $91(80-98)^{* * * *}$ \\
\hline FVC (range), L & $3.4(2.7-4.2)$ & $2.8(2.2-3.2)$ & $3.8(3.0-4.3)^{* * *}$ \\
\hline FVC (range), \%p & $90(78-101)$ & $74(63-82)$ & $97(88-104)^{* * * *}$ \\
\hline $\mathrm{FEV}_{1} / \mathrm{FVC}$ (range) & $0.67(0.5 \mathrm{I}-0.74)$ & $0.44(0.37-0.5 \mathrm{I})$ & $0.73(0.67-0.76)^{* * *}$ \\
\hline RV (range), \%p & $122(105-152)$ & $17 \mid(14 \mid-190)$ & $117(96-126)^{* * *}$ \\
\hline TLC (range), \%p & $109(100-116)$ & II (107-129) & $108(100-113)^{* *}$ \\
\hline \multicolumn{4}{|l|}{ Impulse oscillometry } \\
\hline R5 (range), \%p & $105(83-127)$ & $150(124-199)$ & $94(75-108)^{* * *}$ \\
\hline R20 (range), \%p & $88(7 \mid-107)$ & $100(84-145)$ & $83(67-94)^{* * * *}$ \\
\hline R5-R20 (range), \%p & $183(100-342)$ & $400(284-681)$ & $133(83-233)^{* * *}$ \\
\hline X5 (range), \%p & $306(178-566)$ & $587(966-314)$ & $226(144-366)^{* * *}$ \\
\hline \multicolumn{4}{|c|}{ Helium diffusion carbon monoxide diffusion } \\
\hline $\mathrm{D}_{\mathrm{L}, \mathrm{CO}}$ (range), \%p & $67(5 \mathrm{I}-77)$ & $46(34-53)$ & 7I $(65-80)^{* * *}$ \\
\hline $\mathrm{VA}$ (range), \%p & $87(80-96)$ & $79(7 \mid-87)$ & $90(86-97)^{* * *}$ \\
\hline $\mathrm{D}_{\mathrm{L}, \mathrm{CO}} / \mathrm{VA}$ (range), \%p & $77(6 I-91)$ & $59(51-66)$ & $82(72-93)^{* * *}$ \\
\hline
\end{tabular}

Notes: $* * P<0.01$ and $* * * P<0.001$, compared to Group I.

Abbreviations: $\mathrm{FEV}, \%$, forced expiratory volume in I second percent predicted; BMI, body mass index; SABA, short-acting $\beta 2$ agonist; LAMA, long-acting muscarinic antagonist; LABA, long-acting $\beta 2$ agonist; CCQ, Clinical COPD Questionnaire; FVC, forced vital capacity; RV, residual volume; TLC, total lung capacity; VA, alveolar volume; ICS, inhaled corticosteroids.

relation to post-bronchodilator $\mathrm{FEV}_{1} \% \mathrm{p}$. The light gray line shows the smooth loess; the straight line the LR; and the broken line, where half the line is dotted, is the segmented linear regression (SLR). The dot in Figure 2B shows where the BP is with $95 \%$ confidence interval. BP is given as

Impulse oscillometry, body plethysmography, CO diffusion (duration approximately 1 hour)

Inhalation of salbutamol

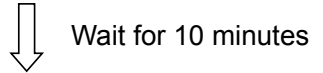

Impulse oscillometry, body plethysmography, CO diffusion (duration approximately 1 hour)

Inhalation of ipratropium

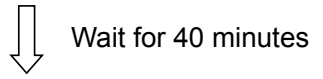

Impulse oscillometry, body plethysmography, $\mathrm{CO}$ diffusion (duration approximately 1 hour)

Figure I Flowchart of the study design.
$\mathrm{FEV}_{1} \% \mathrm{p}$. The estimated LR (Figure $2 \mathrm{~A}$ ) or SLR (if significant over LR; Figure 2B) of each graph is then plotted into one graph to visualize the lung function before and after SABA+SAMA (Figure 2C), which shows a shift of the curves. This method is also applied in graphs in Figure 3A-D. LR and SLR were also investigated in the absolute response in Figure 4A-D.

All responses shown in Tables 2-4 and S1 are displayed as absolute response $(\Delta)^{29}$ and with parameters expressed as $\% \mathrm{p}$ when possible.

Normally distributed ( $\mathrm{FEV}_{1}, \mathrm{FVC}, \mathrm{FVC} \% \mathrm{p}$ and $\left.\mathrm{IC} \% \mathrm{p}\right)$ paired data were analyzed using analysis of variance with Bonferroni's multiple comparison test, and uneven distributed paired data were analyzed using Friedman test with Dunn's multiple comparison test. Normally distributed unpaired data were analyzed using Unpaired students $t$-test, and uneven distributed unpaired data were analyzed using Mann-Whitney $U$ test. Data are presented as median with interquartile range. A $P$-value $<0.05$ was considered significant. Statistical calculations were performed in R or GraphPad Prism (version 5). 
A

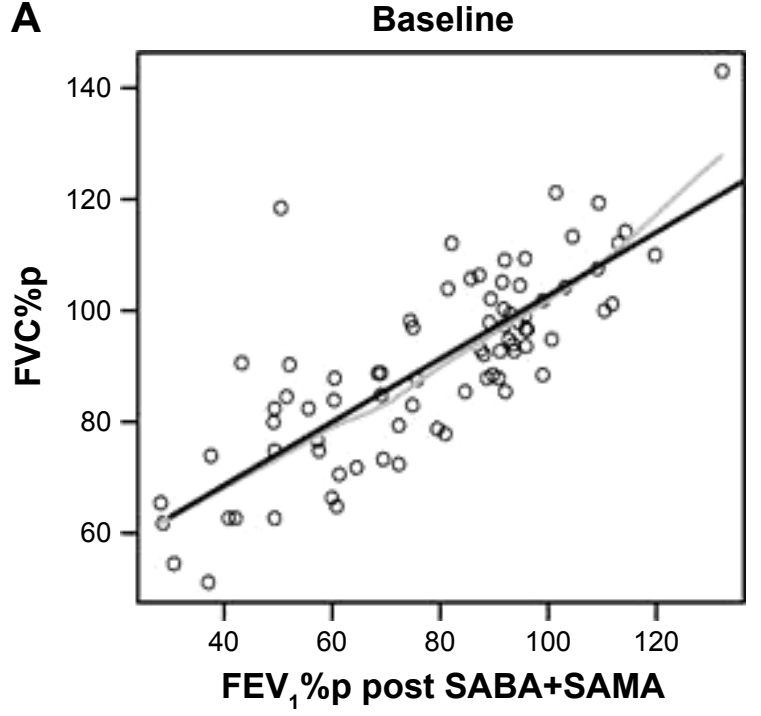

C

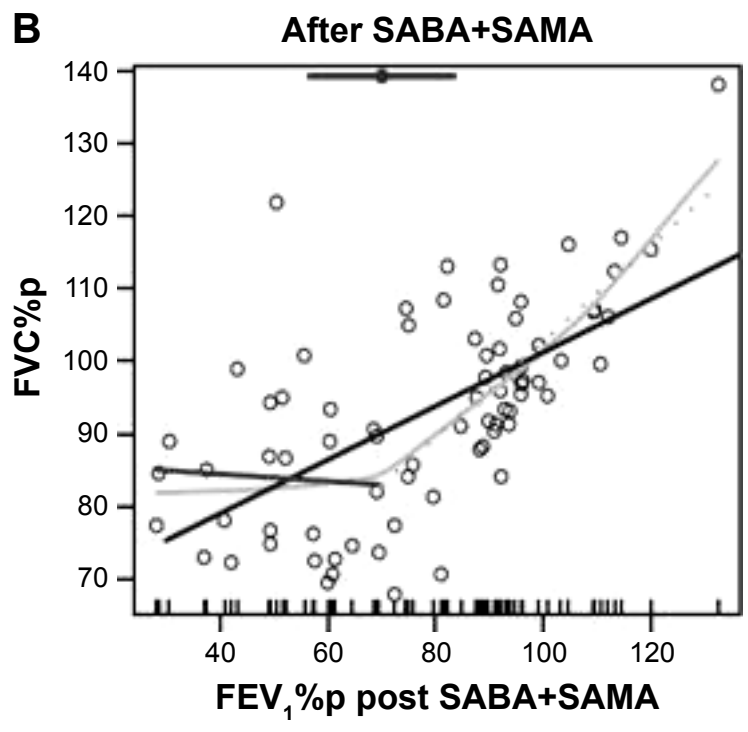

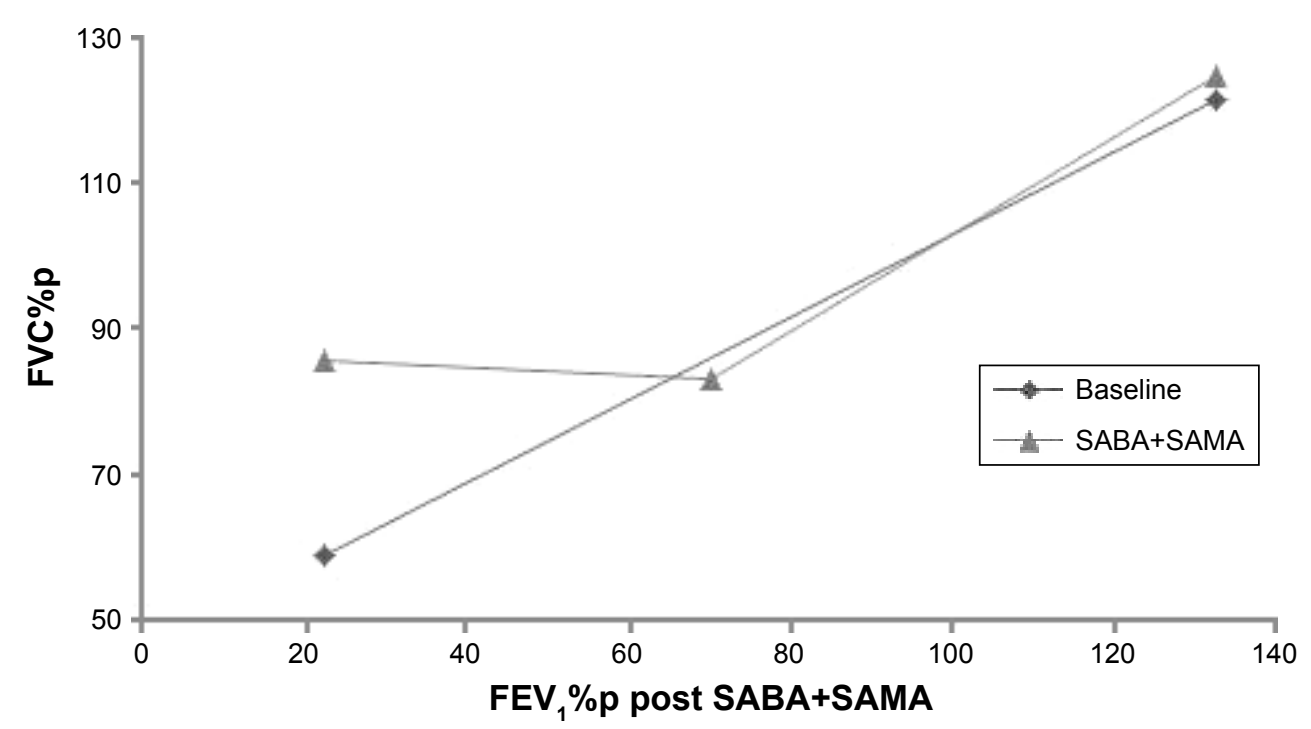

Figure 2 FVC\%p at (A) baseline and (B) after inhalation of SABA and additional SAMA in COPD patients and controls.

Notes: The solid line to left and the hatched line to right of the BP are the segmented linear fits that join at the BP, estimated in the top of the figure (circles with the associated $95 \%$ confidence intervals). An ordinary LR line (hatched gray) and the reference and a nonparametric fit by the loess (local regression) method (gray line) are also displayed. Dots show the values of each subject. (C) The first two (A and $\mathbf{B})$ linear/segmented linear curves plotted into one graph to illustrate bronchodilator response. Abbreviations: FVC, forced vital capacity; \%p, percent predicted; SABA, short-acting $\beta 2$ agonist; SAMA, short-acting muscarinic antagonist; BP, break point; LR, linear regression.

\section{Results}

\section{Continuous analysis of lung function at} baseline and after inhalation of SABA

\section{with additional SAMA}

Most of the parameters that show linearity or segmented linearity at baseline maintain this pattern even after inhalation of SABA with additional SAMA, except FVC\%p (Figure 2), $\mathrm{FEV}_{1} / \mathrm{FVC}$ (Figure 3A), IC\%p (Figure 3B) and $R_{\mathrm{ex}}$ (Figure 3C).

$\mathrm{FVC} \% \mathrm{p}$ and IC $\% \mathrm{p}$ change from favoring linear relationship at baseline to segmented relationship after inhalation of SABA+SAMA, while $R_{\text {ex }}$ changes from being segmented at baseline to linear after inhalation of SABA+SAMA. FEV ${ }_{1}$ FVC shows BPs at both tests, but the BP is much lower after inhalation of SABA+SAMA.

\section{Continuous analysis of absolute response to SABA with additional SAMA}

The bronchodilator response to SABA+SAMA was analyzed for LR and SLR, and the following parameters showed a significant SLR (BP within parenthesis; Figure 4; Table 2), ie, the same parameters change their pattern as described earlier (Figure 3): $\Delta \mathrm{FVC} \% \mathrm{p}(58 \%$; Figure $4 \mathrm{~A}), \Delta \mathrm{FEV}_{1} / \mathrm{FVC}(52 \%$; Figure 4B), $\Delta \mathrm{IC} \%\left(57 \%\right.$; Figure 4C) and $\Delta R_{\text {ex }}$ (44\%; Figure 4D). 

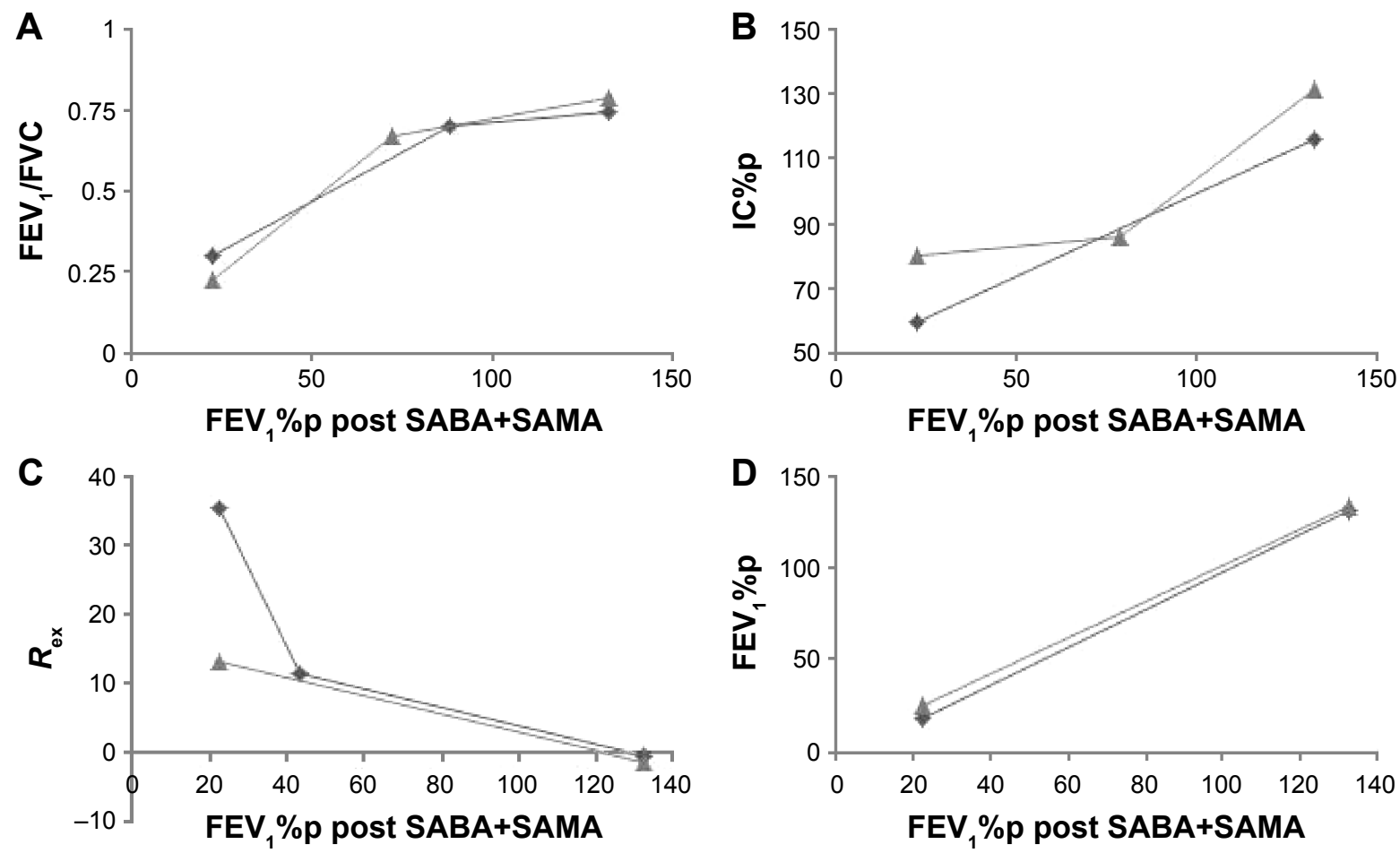

$\multimap$ Baseline $\longrightarrow$ SABA+SAMA

Figure 3 Lungfunction, before and after bronchodilators.

Notes: (A) FEV $/$ /FVC, (B) IC\%p, (C) $R_{\text {ex }}$ and (D) FEV \%p at baseline and after inhalation of SABA and additional SAMA in COPD patients and controls. Graphs show linear regression lines or segmented regression lines (if segmentation was significant).

Abbreviations: $\mathrm{FEV}_{1}$, forced expiratory volume in I second; FVC, forced vital capacity; IC, inspiratory capacity; \%p, percent predicted; SABA, short-acting 32 agonist; SAMA, short-acting muscarinic antagonist.

All the four parameters showed a significant slope at the left side of the BP (= at low $\mathrm{FEV}_{1} \%$ p), while the slope to the right (= at high $\mathrm{FEV}_{1} \% \mathrm{p}$ ) was not significant (Table 2).

The following parameters showed a significant LR slope when the response was linearly increasing to a decrease in $\mathrm{FEV}_{1} \% \mathrm{p}$ (Table 2): $\Delta \mathrm{RV} \% \mathrm{p}, \Delta \mathrm{FRC} \% \mathrm{p}, \Delta R_{\text {in }}, \Delta \mathrm{Rtot} \% \mathrm{p}$, $\Delta \mathrm{D}_{\mathrm{L}, \mathrm{CO}} \% \mathrm{p}, \Delta \mathrm{R} 5 \% \mathrm{p}, \Delta \mathrm{R} 5-\mathrm{R} 20 \% \mathrm{p}$ and $\Delta \mathrm{AX}$.

The remaining parameters showed no significant LR slope or SLR (Table 2), but $\Delta \mathrm{FEV}_{1} \% \mathrm{p}, \Delta \mathrm{X} 5 \% \mathrm{p}$ and $\Delta \mathrm{D}_{\mathrm{L}, \mathrm{CO}} /$ VA\%p showed significant intercepts, indicating a similar response over the severity range. $\Delta \mathrm{TLC} \% \mathrm{p}, \Delta \mathrm{R} 20 \% \mathrm{p}$ and $\Delta \mathrm{VA} \% \mathrm{p}$ showed no significant slope or intercept, indicating an insignificant response over the severity range.

\section{Response to SABA with additional SAMA in subjects with FEV \% $\% 65$ or $>65$}

In our previous study, ${ }^{3}$ several parameters had BPs around $\mathrm{FEV}_{1} 65 \%$ p. A related pattern is shown in this study, investigating the continuous relationship between the bronchodilator response and $\mathrm{FEV}_{1} \% \mathrm{p}$. To investigate the potential difference in the bronchodilator response (compared to baseline) of the different lung function parameters, the subjects were therefore further divided into groups of $\mathrm{FEV}_{1} \% \mathrm{p}<65$ and $>65$ (Tables 1 and 3).

Some of the lung volume parameters showed a significant bronchodilator response only in patients with $\mathrm{FEV}_{1} \% \mathrm{p}<65$ (Table 3): RV\%p and FVC\%p.

Other lung function parameters showed a significant bronchodilator response in both the groups $\left(\mathrm{FEV}_{1} \% \mathrm{p}<65\right.$ and $>65$ ) (Table 3): $\mathrm{FEV}_{1} \%$ p, FRC\%p, IC\%p, $\mathrm{FEV}_{1}, \mathrm{R} 5 \% \mathrm{p}$, $\mathrm{R} 5-\mathrm{R} 20 \% \mathrm{p}, \mathrm{X} 5 \% \mathrm{p}, \mathrm{AX}, F_{\mathrm{res}}, R_{\text {in }}, R_{\mathrm{ex}}$ and Rtot $\% \mathrm{p}$.

All the above parameters showed a significantly higher bronchodilator response for the group below $\mathrm{FEV}_{1} \% \mathrm{p}<65$, except: $\mathrm{FEV}_{1}$, IC\%p, R20\%p and $F_{\text {res. }}$.

The remaining parameters showed no response to the bronchodilator (or very little; data not shown): TLC\%p, $\mathrm{D}_{\mathrm{L}, \mathrm{CO}} \% \mathrm{p}, \mathrm{VA} \% \mathrm{p}$ and $\mathrm{D}_{\mathrm{L}, \mathrm{CO}} / \mathrm{VA} \% \mathrm{p}$.

\section{Correlation between response in flow, volume, resistance and reactance parameters to SABA with additional SAMA}

The correlations between $\Delta \mathrm{FEV}_{1} \% \mathrm{p}$ (flow), $\Delta \mathrm{FVC} \% \mathrm{p}$ (flow volume), $\Delta \mathrm{RV} \% \mathrm{p}$ (volume), $\Delta \mathrm{R}$ tot $\% \mathrm{p}$ (resistance), 

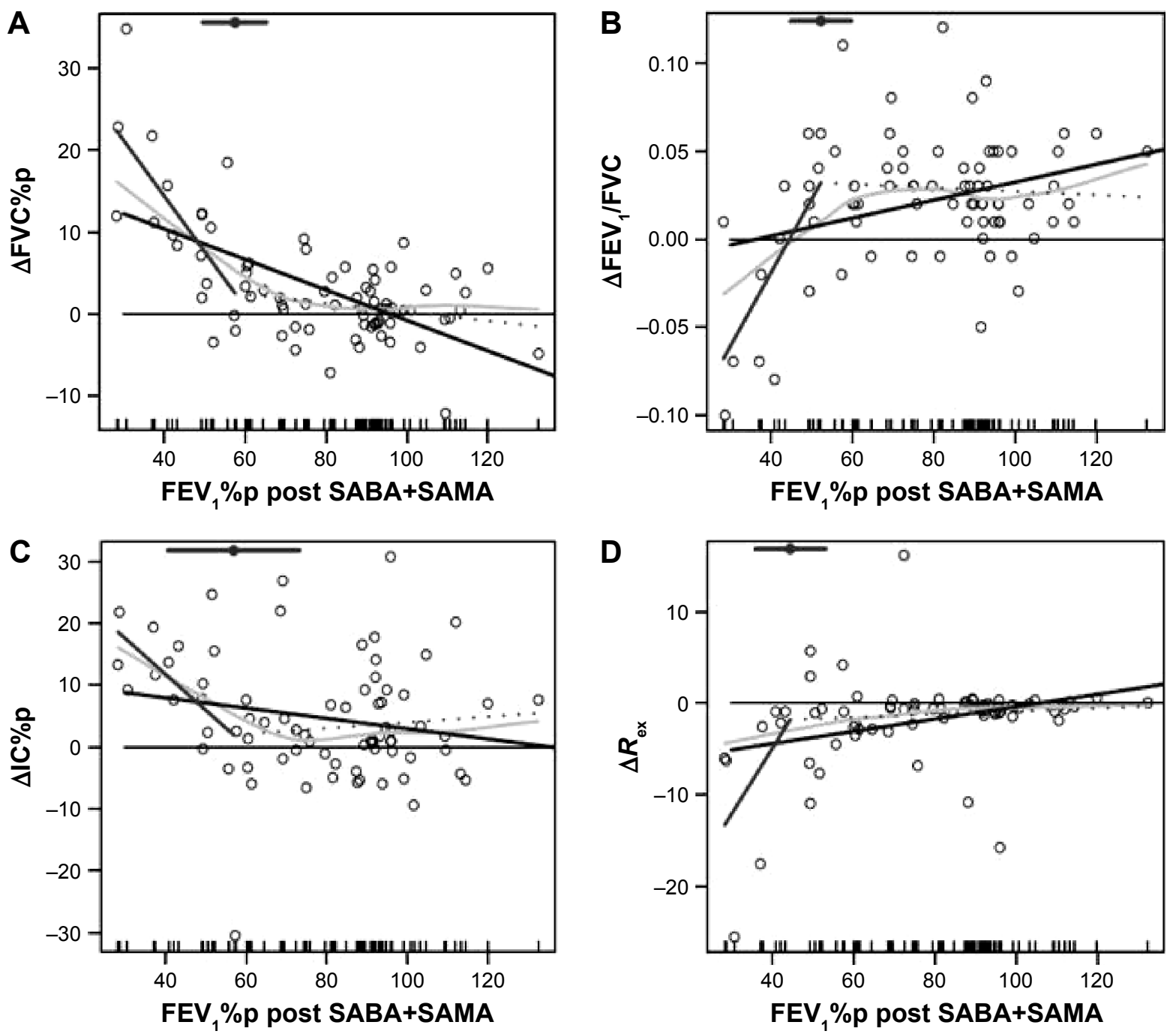

Figure 4 Bronchodilator response.

Notes: (A) $\Delta \mathrm{FVC} \%,(\mathbf{B}) \Delta \mathrm{FEV} / \mathrm{FVC},(\mathbf{C}) \Delta \mathrm{IC} \% \mathrm{p}$ and (D) $\Delta R_{\mathrm{ex}}$ in COPD patients and controls. The solid line to the left and the hatched line to the right of the BP are the segmented linear fits that join at the BP, estimated in the top of the figure (circles with the associated $95 \%$ confidence intervals). An ordinary LR line (hatched gray) and the reference and a nonparametric fit by the loess (local regression) method (gray line) are also displayed. Dots show the values of each subject.

Abbreviations: FVC, forced vital capacity; FEV , forced expiratory volume in I second; IC, inspiratory capacity; \%p, percent predicted; BP, break point; LR, linear regression, SABA, short-acting $\beta 2$ agonist (salbutamol); SAMA, short-acting muscarinic antagonist (ipratropium).

R5-R20\%p (peripheral resistance) and $\triangle \mathrm{AX}$ (reactance) were investigated to define the relationship within the response of different lung function parameters. In subjects with $\mathrm{FEV}_{1} \% \mathrm{p}<65, \Delta \mathrm{FEV}_{1} \% \mathrm{p}$ correlated only with $\Delta \mathrm{FVC} \% \mathrm{p}$, while $\Delta \mathrm{FVC} \% \mathrm{p}, \Delta \mathrm{RV} \% \mathrm{p}, \Delta \mathrm{R}$ tot $\% \mathrm{p}$ and $\Delta \mathrm{AX}$ correlated with most of each other (Table 4). In contrast, in subjects with $\mathrm{FEV}_{1} \% \mathrm{p}>65, \Delta \mathrm{FEV}_{1} \% \mathrm{p}$ correlated with $\Delta \mathrm{FVC} \% \mathrm{p}$, $\triangle \mathrm{R} 5-\mathrm{R} 20 \% \mathrm{p}$ and $\triangle \mathrm{AX}$, while no correlations were found among $\Delta \mathrm{FVC} \% \mathrm{p}, \Delta \mathrm{RV} \% \mathrm{p}, \Delta \mathrm{R}$ tot $\% \mathrm{p}$ and $\Delta \mathrm{AX}$ (Table 4).

Response in volume, resistance and reactance correlated with each other but not with $\mathrm{FEV}_{1} \%$ p. To visualize the relationships and the individual responses, $\Delta \mathrm{RV} \% \mathrm{p}$ was plotted against $\Delta \mathrm{FEV}_{1} \% \mathrm{p}$ (Figure 5). Some patients were both flow and volume responders, while some were either flow or volume responders, but no clear grouping could be demonstrated. Flow responders were defined as having a response in $\mathrm{FEV}_{1} \% \mathrm{p}$ above the median response in this cohort, while volume responders were defined as having a response in $\mathrm{RV} \% \mathrm{p}$ above the median response in this cohort. With this definition, 18 subjects ( 11 controls and 7 COPD) were classified as neither flow nor volume responders (nonresponders in Figure 5).

\section{Analysis of response to only SABA}

All patients were also tested for the response to only SABA. A similar pattern was seen for the "continuous analysis of lung function at baseline and after inhalation of SABA" and for the "continuous analysis of absolute response to SABA" 
Table 2 LR and SLR for lung function response to SABA and additional SAMA

\begin{tabular}{|c|c|c|c|c|c|c|}
\hline Parameters & $\operatorname{LR}$ or $\operatorname{SLR}^{\mathrm{a}}(\mathrm{BP})^{\mathrm{b}}$ & $\begin{array}{l}P \text {-value } \\
\text { for BP }\end{array}$ & Slope (left/right) ${ }^{c}$ & $\begin{array}{l}\text { P-value for slope } \\
\text { (left/right) }^{\mathrm{d}}\end{array}$ & Intercept ${ }^{\mathrm{e}}$ & $\begin{array}{l}P \text {-value for } \\
\text { intercept }^{f}\end{array}$ \\
\hline$\Delta \mathrm{FVC} \% \mathrm{p}$ & SLR (58) & $<0.00 \mathrm{I}$ & $-0.68 /-0.05$ & $<0.001 / 0.150$ & 41.69 & $<0.00 \mathrm{I}$ \\
\hline$\Delta \mathrm{FEV}_{1} / \mathrm{FVC}$ & SLR (52) & $<0.00$ I & $0.00 / 0.00$ & $<\mathbf{0 . 0 0 1 / 0 . 6 7 0}$ & -0.19 & $<0.00$ I \\
\hline$\Delta \mathrm{IC} \% \mathrm{p}$ & SLR (57) & 0.044 & $-0.58 / 0.05$ & $0.036 / 0.516$ & 35.22 & 0.004 \\
\hline$\Delta R_{\mathrm{ex}}$ & SLR (44) & 0.004 & $0.72 / 0.02$ & $\mathbf{0 . 0 0 1 / 0 . 5 3 3}$ & -33.59 & 0.001 \\
\hline$\Delta R_{\text {in }}$ & LR & ns & 0.02 & $<0.001$ & -2.10 & $<0.001$ \\
\hline$\Delta$ Rtot $\% p$ & LR & ns & 1.05 & $<0.00$ I & -116.26 & $<0.00$ I \\
\hline$\Delta \mathrm{AX}$ & LR & ns & 0.01 & $<0.001$ & -1.23 & $<0.001$ \\
\hline$\Delta \mathrm{RV} \% \mathrm{p}$ & LR & ns & 0.37 & 0.001 & -37.47 & $<0.00 \mathrm{I}$ \\
\hline$\Delta R 5-R 20 \% p$ & LR & ns & 1.41 & 0.004 & -169.50 & $<0.00 \mathrm{I}$ \\
\hline$\Delta \mathrm{FRC} \% \mathrm{p}$ & LR & ns & 0.14 & 0.026 & -16.67 & 0.001 \\
\hline$\Delta \mathrm{D}_{\mathrm{L}, \mathrm{CO}} \% \mathrm{p}$ & LR & ns & -0.06 & 0.029 & 4.92 & 0.040 \\
\hline$\Delta \mathrm{R} 5 \% \mathrm{p}$ & LR & ns & 0.20 & 0.046 & -31.91 & $<0.001$ \\
\hline$\Delta \mathrm{FEV}, \% \mathrm{p}$ & LR & ns & -0.03 & 0.144 & 7.04 & $<0.001$ \\
\hline$\Delta \times 5 \% p$ & LR & ns & 5.20 & 0.056 & 600.25 & 0.008 \\
\hline$\Delta \mathrm{D}_{\mathrm{L}, \mathrm{co}} / \mathrm{VA} \% \mathrm{p}$ & LR & ns & -0.06 & 0.061 & 5.58 & 0.029 \\
\hline$\Delta \mathrm{R} 20 \% \mathrm{p}$ & LR & ns & 0.02 & 0.746 & -11.33 & 0.062 \\
\hline$\Delta \mathrm{TLC} \% \mathrm{p}$ & LR & ns & 0.03 & 0.384 & -3.37 & 0.243 \\
\hline$\Delta \mathrm{VA} \% \mathrm{p}$ & LR & ns & -0.03 & 0.096 & I.7I & 0.306 \\
\hline
\end{tabular}

Notes: Bold numbers indicate significance $(P<0.05)$. $\Delta$ indicates absolute response. aparameter is labeled SLR if there is a significant SLR (defined from $P$-value in the next column: "P-value for BP"), otherwise it is labeled LR. 'The subsequent BP from the SLR is shown in parentheses. "Slope (left/right) is the slope of the linear regression line or the slope of the two regression lines if there is a significant segmented linear regression (then the slopes of the regression lines [left and right] of the BP are shown within parentheses). ${ }^{d} P$-value for slope (left/right) indicates if the slope is significant (ie, if there is a slope that is different from a horizontal line). Intercept indicates where the regression line crosses the $Y$-axis. ${ }^{f} P$-value for intercept indicates a significant response (ie, the response lines are significantly different from a horizontal line at $y=0$ ). Abbreviations: LR, linear regression; SLR, segmented linear regression; SABA, short-acting $\beta 2$ agonist (salbutamol); SAMA, short-acting muscarinic antagonist (ipratropium); $\mathrm{BP}$, break point; FVC, forced vital capacity; FEV , forced expiratory volume in I second; \%p, percent predicted; IC, inspiratory capacity; AX, reactance area; RV, residual volume; FRC, functional residual capacity; VA, alveolar volume; TLC, total lung capacity.

Table 3 Absolute response of lung function parameters after SABA with additional SAMA

\begin{tabular}{|c|c|c|c|}
\hline Parameters & Group I $($ FEV $\%$ < 65$)$ & Group $2($ FEV $\%>65)$ & Significance $^{a}$ \\
\hline \multicolumn{4}{|c|}{ Body plethysmography } \\
\hline$\Delta \mathrm{FEV}_{1}(\mathrm{~L})$ & $0.21(0.10$ to 0.25$)$ & $0.10(0.04$ to 0.19$)$ & ns \\
\hline$\Delta \mathrm{FEV}, \% \mathrm{p}$ & $6.0(3.1$ to 8.9$)$ & $3.3(1.5$ to 6.5$)$ & $*$ \\
\hline$\Delta \mathrm{FVC}(\mathrm{L})$ & $0.35(0.10$ to 0.52$)$ & $0.01(-0.07$ to 0.12$)$ & $* * *$ \\
\hline$\Delta \mathrm{FVC} \% \mathrm{p}$ & $9.6(3.3$ to I5.6) & $0.5(-1.5$ to 2.8$)$ & $* * *$ \\
\hline$\Delta \mathrm{FEV}_{1} / \mathrm{FVC}$ & 0.01 ( -0.02 to 0.03$)$ & $0.03(0.01$ to 0.05$)$ & $*$ \\
\hline$\Delta \mathrm{RV}(\mathrm{L})$ & $-0.46(-0.82$ to -0.06$)$ & $-0.04(-0.26$ to 0.14$)$ & $* * *$ \\
\hline$\Delta \mathrm{RV} \% \mathrm{p}$ & $-20.9(-39.7$ to -2.2$)$ & $-2.2(-12.0$ to 5.9$)$ & $* *$ \\
\hline$\Delta \mathrm{FRC} \% \mathrm{p}$ & $-11.9(-16.6$ to -3.9$)$ & $-4.2(-11.2$ to 2.2$)$ & $* *$ \\
\hline$\Delta \mathrm{IC} \% \mathrm{p}$ & $7.8(2.4$ to 13.7$)$ & $1.4(-2.1$ to 7.2$)$ & ns \\
\hline$\Delta R_{\mathrm{ex}}(\mathrm{kPa} \cdot \mathrm{s} / \mathrm{L})$ & $-2.29(-6.14$ to -0.76$)$ & $-0.60(-1.03$ to -0.16$)$ & $* *$ \\
\hline$\Delta R_{\text {in }}(\mathrm{kPa} \cdot \mathrm{s} / \mathrm{L})$ & $-1.23(-2.30$ to -0.51$)$ & $-0.45(-0.63$ to -0.14$)$ & $* * *$ \\
\hline$\Delta$ Rtot\%p & $-55.5(-95.6$ to -21.3$)$ & $-15.2(-26.8$ to -4.5$)$ & $* * *$ \\
\hline \multicolumn{4}{|c|}{ Impulse oscillometry } \\
\hline$\Delta \mathrm{R} 5 \% \mathrm{p}$ & $-27.1(-45.9$ to -11.7$)$ & $-13.9(-20.8$ to -4.5$)$ & $* *$ \\
\hline$\Delta R 20 \% p$ & $-11.9(-22.2$ to -1.3$)$ & $-9.0(-17.5$ to -2.5$)$ & ns \\
\hline$\Delta R 5-R 20 \% p$ & $-117.0(-250.0$ to -25.0$)$ & $-33.0(-75.0$ to 0.0$)$ & $* *$ \\
\hline$\Delta F_{\text {res }}(\mathrm{Hz})$ & $-1.84(-3.51$ to -0.47$)$ & $-1.54(-4.12$ to -0.03$)$ & ns \\
\hline$\Delta \times 5 \% p$ & $-102.9(-226.2$ to -21.7$)$ & $-47.6(-94.9$ to -22.1$)$ & $*$ \\
\hline$\Delta \mathrm{AX}(\mathrm{kPa} / \mathrm{L})$ & $-0.54(-1.39$ to -0.11$)$ & $-0.08(-0.37$ to -0.01$)$ & $* *$ \\
\hline \multicolumn{4}{|c|}{ Single-breath helium dilution carbon monoxide diffusion } \\
\hline$\Delta \mathrm{D}_{\mathrm{L}, \mathrm{CO}} \% \mathrm{p}$ & $2.0(-2.5$ to 3.5$)$ & $0.0(-4.0$ to 3.0$)$ & ns \\
\hline
\end{tabular}

Notes: Data show median response (and IQR) within each group. Bold numbers indicate significant bronchodilator response compared to baseline. aSignificant difference between Group I and Group 2 in response $\left(* P<0.05\right.$, ${ }^{*} * P<0.01$ and $\left.* * * P<0.00 I\right)$. ns, no significant difference. $\Delta$ indicates absolute response.

Abbreviations: SABA, short-acting $\beta 2$ agonist (salbutamol); SAMA, short-acting muscarinic antagonist (ipratropium); FEV , forced expiratory volume in I second; \%p, percent predicted; FVC, forced vital capacity; RV, residual volume; FRC, functional residual capacity; IC, inspiratory capacity; AX, reactance area; IQR, interquartile range. 
Table 4 Correlation between absolute response in lung function parameters (in $\triangle$ values) after inhalation of SABA+SAMA

\begin{tabular}{|c|c|c|c|c|c|}
\hline & $\Delta$ FEV,$\% p$ & $\Delta F V C \% p$ & $\Delta$ Rtot $\% p$ & $\Delta \mathbf{R V} \% \mathbf{p}$ & $\Delta \mathbf{R 5}-\mathbf{R} 20 \%$ p \\
\hline \multicolumn{6}{|c|}{ Group I (FEV \% <65) } \\
\hline$\Delta \mathrm{FVC} \% \mathrm{p}$ & $0.44 *$ & & & & \\
\hline$\Delta$ Rtot $\% p$ & -0.34 & $-0.7 I^{* * *}$ & & & \\
\hline$\Delta R V \% p$ & -0.29 & $-0.6 \mathrm{I} * * *$ & -0.06 & & \\
\hline$\Delta \mathrm{R} 5-\mathrm{R} 20 \% \mathrm{p}$ & -0.14 & -0.18 & 0.29 & $0.44^{*}$ & \\
\hline$\Delta \mathrm{AX}$ & -0.32 & $-0.4 I^{*}$ & $0.46 *$ & $0.40 *$ & $\mathbf{0 . 8 7} * * *$ \\
\hline \multicolumn{6}{|c|}{ Group 2 (FEV \% > 65) } \\
\hline$\Delta \mathrm{FVC} \% \mathrm{p}$ & $0.56^{* * * *}$ & & & & \\
\hline$\Delta$ Rtot $\% p$ & -0.09 & -0.21 & & & \\
\hline$\Delta \mathrm{RV} \% \mathrm{p}$ & -0.13 & -0.27 & 0.22 & & \\
\hline$\Delta \mathrm{R} 5-\mathrm{R} 20 \% \mathrm{p}$ & $-0.36 * *$ & -0.11 & -0.12 & 0.17 & \\
\hline$\Delta \mathrm{AX}$ & $-0.36 * *$ & -0.23 & 0.04 & 0.14 & $0.80 * * *$ \\
\hline
\end{tabular}

Notes: $\Delta$ indicates the absolute response in each parameter after inhaling SABA+SAMA. $* P<0.05, * * P<0.01$, and $* * * P<0.00$ I show significance of the correlation (significant correlations are bolded for clarification). Numbers presented as correlation coefficients.

Abbreviations: SABA, short-acting $\beta 2$ agonist; SAMA, short-acting muscarinic antagonist; FEV , forced expiratory volume in I second; \%p, percent predicted; FVC, forced vital capacity; $R V$, residual volume; $A X$, reactance area.

(Table S1) as for the double bronchodilators. Although $\mathrm{FEV}_{1} / \mathrm{FVC}$ did not show any response, $\mathrm{D}_{\mathrm{L}, \mathrm{CO}} \% \mathrm{p}$ and $\mathrm{R} 5 \% \mathrm{p}$ did not have a significant slope, while R20\%p did have. For "response to SABA in subjects with $\mathrm{FEV}_{1} \% \mathrm{p}<65$ or $>65$ ", there seemed to be less effect of only SABA on several parameters compared to SABA+SAMA (Table S2). When looking at the "correlations between flow/volume/ resistance/reactance response to SABA", a similar pattern was observed for SABA+SAMA with few correlations to $\triangle \mathrm{FEV}_{1}$ in the $\mathrm{FEV}_{1} \% \mathrm{p}<65$ group, but to all except volume in the $\mathrm{FEV}_{1} \% \mathrm{p}>65$ group (Table S3).

\section{Discussion}

In this study, we found that several volume and resistance parameters (measured by body plethysmography and IOS)

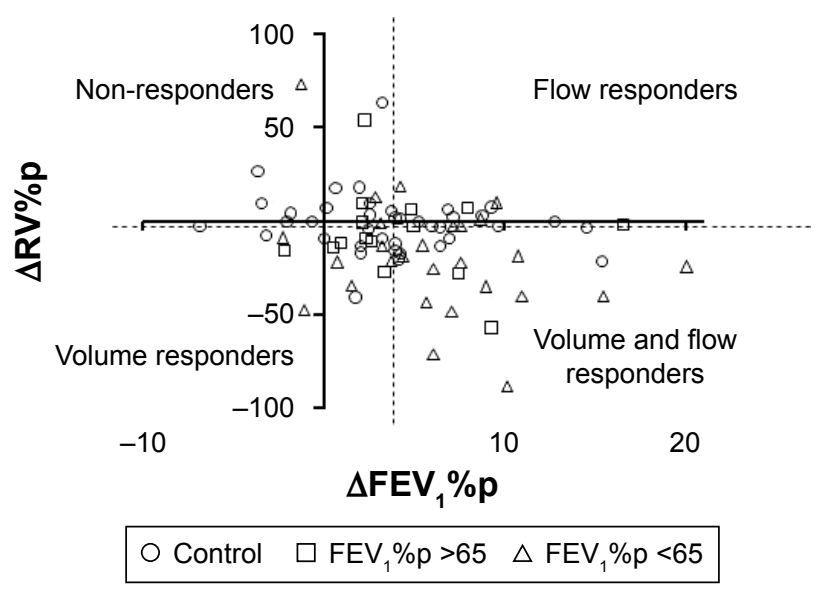

Figure 5 Relationship between $\Delta \mathrm{FEV}, \% \mathrm{p}$ and $\Delta \mathrm{RV} \% \mathrm{p}$.

Notes: To visualize the flow versus volume response in each patient. Dotted lines are median of $\triangle \mathrm{FEV} \% \mathrm{p}$ and $\triangle \mathrm{RV} \% \mathrm{p}$.

Abbreviations: $\mathrm{FEV}_{1}$, forced expiratory volume in I second; \%p, percent predicted; $\mathrm{RV}$, residual volume. differ from the response pattern seen in $\mathrm{FEV}_{1} \% \mathrm{p}$. We found that parameters reflecting volume response were more prominent in patients with more severe stage of COPD, while resistance parameters were more significant in less advanced stage. Most of the resistance and reactance parameters from IOS and body plethysmography responded to SABA, while the volume parameters were affected only mainly in patients with $\mathrm{FEV}_{1} \% \mathrm{p}<65$ or in patients who needed not only SABA but also the addition of SAMA to gain a significant effect.

The overall clinical aim in COPD should be to improve function in the small peripheral airways both by improving flow and by decreasing the degree of alveolar hypoventilation (flow responders) as well as decreasing air trapping and hyperinflation (volume responders). The degree of air trapping relates to the degree of dyspnea and the functional aspects, including BODE index as a composite score. ${ }^{30}$ In order to evaluate the effect of bronchodilators, it is thus important to go beyond the information provided by $\mathrm{FEV}_{1}$, mainly reflecting flow resistance in the central airways. ${ }^{4}$ These results indicate that the use of $\mathrm{FEV}_{1} \% \mathrm{p}$ as a tool to investigate the effect of bronchodilators is not representative of the changes occurring in the respiratory system. Also, the bronchodilator response of many parameters, such as RV and Rtot, tends to be greater in patients with more severe disease (lower $\mathrm{FEV}_{1} \% \mathrm{p}$ ) and not correlating to the $\mathrm{FEV}_{1} \%$ p response. The addition of SAMA to SABA seems to be most effective in more severe patients whose volume parameters are affected, although data show that the combination of therapies can be beneficial to patients already in an early stage.

Regarding the response of IOS parameters, most of the parameters showed a better response with more severe disease, as previously stated. This is almost in accordance with the 
findings of da Costa et a ${ }^{15}$ regarding bronchodilator response using FOT, since we had more patients with milder disease.

Response to SABA was $1.4 \%-4 \%$ (40-120 mL), which is very low compared to the clinically relevant response. ${ }^{31}$ Additional inhalation of SAMA increased the response, especially in patients with $\mathrm{FEV}_{1} \% \mathrm{p}<65$, to $6 \%(210 \mathrm{~mL})$. The continuous analysis did not detect higher response in more severe patients (nonsignificant slope), but the intercept was significant and thereby in accordance with the response analysis. Calverley et $\mathrm{al}^{4}$ questioned the clinical relevance of reversibility tests in COPD, which is in line with our SABA data, showing the importance of not only using double bronchodilators for optimal bronchodilation but also addition of other parameters measuring volume, resistance and reactance.

Only patients with lower $\mathrm{FEV}_{1} \% \mathrm{p}\left(\mathrm{FEV}_{1} \% \mathrm{p}<65\right)$ showed a significant response in $\mathrm{RV} \% \mathrm{p}$ and $\mathrm{FVC} \% \mathrm{p}$, and this improvement also differed significantly compared to subjects with $\mathrm{FEV}_{1} \% \mathrm{p}>65 . \Delta \mathrm{FVC} \% \mathrm{p}$ showed a significant SLR with BP at $\mathrm{FEV}_{1} \% \mathrm{p}$ at 57, with no improvement in patients over this BP. This suggests that these improvements are a trait only in patients with more severe COPD and that there is no use in measuring at least $\mathrm{FVC} \% \mathrm{p}$ response over $\mathrm{FEV}_{1} \% \mathrm{p}$ at $57 . \Delta \mathrm{RV} \% \mathrm{p}$ showed a highly significant $\mathrm{LR}$, crossing the $X$-axis around $\mathrm{FEV}_{1} \%$ p at $100 \%$, implying that the response is very low in high $\mathrm{FEV}_{1} \% \mathrm{p}$ but gradually increases as the disease progresses.

All parameters (except for $F_{\text {res }}$ ) that were significantly reversible in both groups to SABA and SABA+SAMA showed a significantly higher improvement in patients with more severe COPD. These data imply that the main effects of bronchodilators on lung function parameters other than $\mathrm{FEV}_{1} \% \mathrm{p}$ are in the more severe group.

When the correlations and relationship of the difference in bronchodilator response were investigated, we observed a bronchodilator effect in the volume, resistance and reactance, beyond what can be measured with $\triangle \mathrm{FEV}_{1} \% \mathrm{p}$. Data suggest that it might be beneficial to use RV\%p in addition to $\mathrm{FEV}_{1} \% \mathrm{p}$ when evaluating response to bronchodilators, since this parameter did not correlate with $\mathrm{FEV}_{1} \% \mathrm{p}$ but with those of the peripheral airways (R5-R20\%p, AX) in patients with $\mathrm{FEV}_{1} \% \mathrm{p}<65$. This also implies that there might be an importance in measuring the response but that more parameters should be evaluated to provide a fair picture of the response pattern. To visualize if a patient is a flow or a volume responder, the ratio of $\Delta \mathrm{RV} \% \mathrm{p} / \Delta \mathrm{FEV}_{1} \% \mathrm{p}$ may be used, since there seems to be patients being only flow responders, only volume responders, or both flow and volume responders. However, this method should be further verified to define a stable limit, dividing nonresponders from responders. Here, we used the median in the population. Another approach could be using zero response or a set limit (eg, what is clinical relevant). Further characterization of these patient subgroups in a clinical context would be of interest. This could also be applied to identify resistance and reactance parameters by using $\Delta \mathrm{AX} / \Delta \mathrm{FEV} \% \mathrm{p}$ and $\Delta \mathrm{R}$ tot $\% \mathrm{p}$ (or $\Delta \mathrm{R} 5-\mathrm{R} 20 \% \mathrm{p}$ ) $/ \Delta \mathrm{FEV}_{1} \% \mathrm{p}$, respectively.

Many lung function parameters did significantly improve, and many improvements were significantly better in the $\mathrm{FEV}_{1} \% \mathrm{p}<65$ group than in the subjects with $\mathrm{FEV}_{1} \% \mathrm{p}>65$, and this is supported by the fact that many parameters showed LR and SLR in the same direction. This also implies that the changes, even those in the peripheral airways, are only partially irreversible and that patients below the BP could benefit from bronchodilators even if they are not reversible in $\mathrm{FEV}_{1} \% \mathrm{p}$.

A limitation of this study is not only the number of patients but also the distribution of disease severity. Due to difficulties in performing all maneuvers repeatedly or difficulties refraining from medications, the population is a bit skewed toward the milder/moderate disease.

By identifying the parameters that show an effect in response to bronchodilators, it is possible to obtain a deeper understanding about what happens in the airways when bronchodilators are inhaled. By studying these parameters, it would be possible to measure the effectiveness of bronchodilators in different phenotypes/severities of COPD patients. A future perspective is to elucidate if these data hold true in a longitudinal study with long-acting bronchodilators to connect the effects in lung function parameters to those of clinical symptoms and dyspnea.

\section{Conclusion}

Some lung function parameters are significantly reversible along $\mathrm{FEV}_{1} \% \mathrm{p}$, while resistance and volume parameters show different response patterns along the FEV response curve. Measuring the response to resistance may be more informative in milder stages, while volume response parameters are more important in patients with lower $\mathrm{FEV}_{1} \% \mathrm{p}$. Thus, knowing that the bronchodilator effect in volume and resistance does not follow the $\mathrm{FEV}_{1} \%$ p response, those parameters should therefore be considered when characterizing patients according to bronchodilator response. This approach can help us in gaining insight into individualizing the diagnosis and therapy of COPD.

\section{Acknowledgments}

The authors would like to thank the staff at the Lung and Allergy Research Unit, Skåne, and also Dr Anders Olin for 
help and support. This work was supported by independent research grants from the Swedish Heart and Lung Foundation, Swedish Research Council, Evy and Gunnar Sandberg's Foundation, Crafoord Foundation, and Royal Physiographic Society in Lund.

\section{Disclosure}

The authors report no conflicts of interest in this work.

\section{References}

1. Frantz S, Nihlen U, Dencker M, Engstrom G, Lofdahl CG, Wollmer P. Impulse oscillometry may be of value in detecting early manifestations of COPD. Respir Med. 2012;106(8):1116-1123.

2. Jarenback L, Ankerst J, Bjermer L, Tufvesson E. Flow-volume parameters in COPD related to extended measurements of lung volume, diffusion, and resistance. Pulm Med. 2013;2013:782052.

3. Eriksson G, Jarenbäck L, Peterson S, Ankerst J, Bjermer L, Tufvesson E. A new approach to assess COPD by identifying lung function breakpoints. Int J Chron Obstruct Pulmon Dis. 2015;10:2193-2202.

4. Calverley PM, Albert P, Walker PP. Bronchodilator reversibility in chronic obstructive pulmonary disease: use and limitations. Lancet Respir Med. 2013;1(7):564-573.

5. Albert P, Agusti A, Edwards L, et al. Bronchodilator responsiveness as a phenotypic characteristic of established chronic obstructive pulmonary disease. Thorax. 2012;67(8):701-708.

6. Schermer T, Heijdra Y, Zadel S, et al. Flow and volume responses after routine salbutamol reversibility testing in mild to very severe COPD. Respir Med. 2007;101(6):1355-1362.

7. Borrill ZL, Houghton CM, Woodcock AA, Vestbo J, Singh D. Measuring bronchodilation in COPD clinical trials. Br J Clin Pharmacol. 2005; 59(4):379-384.

8. Borrill ZL, Houghton CM, Tal-Singer R, et al. The use of plethysmography and oscillometry to compare long-acting bronchodilators in patients with COPD. Br J Clin Pharmacol. 2008;65(2):244-252.

9. Zerah F, Lorino AM, Lorino H, Harf A, Macquin-Mavier I. Forced oscillation technique vs spirometry to assess bronchodilatation in patients with asthma and COPD. Chest. 1995;108(1):41-47.

10. Timmins SC, Diba C, Schoeffel RE, Salome CM, King GG, Thamrin C. Changes in oscillatory impedance and nitrogen washout with combination fluticasone/salmeterol therapy in COPD. Respir Med. 2014;108(2):344-350.

11. Abe T, Setoguchi Y, Kono Y, et al. Effects of inhaled tiotropium plus transdermal tulobuterol versus tiotropium alone on impulse oscillation system (IOS)-assessed measures of peripheral airway resistance and reactance, lung function and quality of life in patients with COPD: a randomized crossover study. Pulm Pharmacol Ther. 2011; 24(5):617-624.

12. Mineshita M, Shikama Y, Nakajima H, et al; COPD EXHALATION Investigators. The application of impulse oscillation system for the evaluation of treatment effects in patients with COPD. Respir Physiol Neurobiol. 2014;202:1-5.
13. Sinojia R, Shaikh M, Kodgule R, et al. Priming of beta- 2 agonist and antimuscarinic induced physiological responses induced by $1200 \mathrm{mg} /$ day NAC in moderate to severe COPD patients: a pilot study. Respir Physiol Neurobiol. 2014;191:52-59.

14. Newton MF, O'Donnell DE, Forkert L. Response of lung volumes to inhaled salbutamol in a large population of patients with severe hyperinflation. Chest. 2002;121(4):1042-1050.

15. da Costa GM, Faria AC, Di Mango AM, Lopes AJ, Lopes de Melo P. Respiratory impedance and response to salbutamol in healthy individuals and patients with COPD. Respiration. 2014;88(2):101-111.

16. Oostveen E, MacLeod D, Lorino H, et al; ERS Task Force on Respiratory Impedance Measurements. The forced oscillation technique in clinical practice: methodology, recommendations and future developments. Eur Respir J. 2003;22(6):1026-1041.

17. Goldman MD, Smith HJ, Ulmer WT. Whole-body plethysmography. Eur Respir Monogr. 2005;31:15-43.

18. Hughes JMB. Pulmonary gas exchange. Eur Respir Monogr. 2005;31: 106-126.

19. Macintyre N, Crapo RO, Viegi G, et al. Standardisation of the single-breath determination of carbon monoxide uptake in the lung. Eur Respir J. 2005;26(4):720-735.

20. Horstman M, Mertens F, Stam H. Transfer factor for carbon monoxide. Eur Respir Monogr. 2005;31:127-145.

21. Miller MR, Hankinson J, Brusasco V, et al. Standardisation of spirometry. Eur Respir J. 2005;26(2):319-338.

22. Wanger J, Clausen JL, Coates A, et al. Standardisation of the measurement of lung volumes. Eur Respir J. 2005;26(3):511-522.

23. Crapo RO, Morris AH, Gardner RM. Reference spirometric values using techniques and equipment that meet ATS recommendations. Am Rev Respir Dis. 1981;123(6):659-664.

24. Quanjer PH, Tammeling GJ, Cotes JE, Pedersen OF, Peslin R, Yernault JC. Lung volumes and forced ventilatory flows. Report working party standardization of lung function tests, European Community for Steel and Coal. Official Statement of the European Respiratory Society. Eur Respir J Suppl. 1993;16:5-40.

25. Vogel S. Implementation der Sollwertgleichungen für IOS. "ImpulsOszillometrie" pmi-Verlag. 1994:S.148- S.152. German.

26. Muggeo VM. Estimating regression models with unknown break-points. Stat Med. 2003;22(19):3055-3071.

27. Muggeo VM. Segmented: an R package to fit regression models with broken-line relationships. $R$ News. 2008;8/1:20-25.

28. Cleveland WS, Grosse E, Shyu WM. Local regression models. In: Chambers SJM, Hastie TJ, editors. Statistical Models. Wadsworth \& Brooks/Cole; 1992:309-376.

29. Brand PL, Quanjer PH, Postma DS, et al. Interpretation of bronchodilator response in patients with obstructive airways disease. The Dutch Chronic Non-Specific Lung Disease (CNSLD) Study Group. Thorax. 1992;47(6):429-436.

30. Lee YK, Oh Y, Lee J, et al; KOLD Study Group. Quantitative assessment of emphysema, air trapping, and airway thickening on computed tomography. Lung. 2008;186:157.

31. Tan WC, Vollmer WM, Lamprecht B, et al. Worldwide patterns of bronchodilator responsiveness: results from the burden of obstructive lung disease study. Thorax. 2012;67(8):718-726. 


\section{Supplementary materials}

Table SI Continuous analysis of SABA

\begin{tabular}{|c|c|c|c|c|c|c|}
\hline Parameters & LR or SLR (BP\%) & $P$-value for BP & Slope (left/right) & $\begin{array}{l}\text { P-value for slope } \\
\text { (left/right of BP) }\end{array}$ & Intercept & $\begin{array}{l}P \text {-value for } \\
\text { intercept }\end{array}$ \\
\hline$\Delta \mathrm{FVC} \% \mathrm{p}$ & SLR (86) & 0.028 & $-0.21 / 0.06$ & $<0.001 / 0.206$ & 17 & $<0.001$ \\
\hline$\Delta \mathrm{FEV}_{1} / \mathrm{FVC}$ & LR & ns & 0 & 0.091 & -0.015 & 0.277 \\
\hline$\Delta \mathrm{IC} \% \mathrm{p}$ & $\operatorname{SLR}(6 I)$ & 0.033 & $-595 / 0.07$ & $0.10 / 0.451$ & 36 & 0.001 \\
\hline$\Delta R_{\mathrm{ex}}$ & SLR (47) & $<0.001$ & $0.53 / 0.008$ & $0.012 / 0.691$ & -26 & 0.001 \\
\hline$\Delta R_{\mathrm{in}}$ & LR & ns & 0.02 & $<0.001$ & -2.0 & $<0.001$ \\
\hline$\Delta$ Rtot $\% p$ & LR & ns & 0.94 & $<0.00$ I & -99 & $<0.001$ \\
\hline$\Delta \mathrm{AX}$ & LR & ns & 0.01 & 0.003 & -0.87 & $<0.001$ \\
\hline$\Delta R V \% p$ & LR & ns & 0.29 & 0.001 & -28 & $<0.001$ \\
\hline$\Delta R 5-R 20 \% p$ & LR & ns & 1.01 & 0.036 & -116 & 0.004 \\
\hline$\Delta \mathrm{FRC} \% \mathrm{p}$ & LR & ns & 0.12 & 0.027 & -13 & 0.003 \\
\hline$\Delta \mathrm{D}_{\mathrm{L}, \mathrm{CO}} \% \mathrm{P}$ & LR & ns & -0.04 & 0.093 & 4.2 & 0.033 \\
\hline$\Delta R 5 \% p$ & LR & ns & 0.12 & 0.184 & -21 & 0.006 \\
\hline$\Delta \mathrm{FEV}_{1} \% \mathrm{p}$ & LR & ns & -0.03 & 0.128 & 4.8 & 0.004 \\
\hline$\Delta \times 5 \% p$ & LR & ns & 4.86 & 0.076 & -534 & 0.018 \\
\hline$\Delta \mathrm{D}_{\mathrm{L}, \mathrm{co}} / \mathrm{VA} \% \mathrm{p}$ & LR & ns & -0.04 & 0.123 & 5.4 & 0.018 \\
\hline$\Delta R 20 \% p$ & LR & ns & 1.01 & 0.036 & -116 & 0.004 \\
\hline$\Delta \mathrm{TLC} \% \mathrm{p}$ & LR & ns & 0.02 & 0.457 & -2.2 & 0.362 \\
\hline$\Delta \mathrm{VA} \% \mathrm{p}$ & LR & ns & -0.02 & 0.164 & I.I & 0.326 \\
\hline
\end{tabular}

Notes: Bold numbers indicate significance $(P<0.05)$. $\Delta$ indicates absolute response.

Abbreviations: SABA, short-acting $\beta 2$ agonist (salbutamol); LR, linear regression; SLR, segmented linear regression; BP, break point; FVC, forced vital capacity; \%p, percent predicted; $\mathrm{FEV}_{1}$, forced expiratory volume in I second; IC, inspiratory capacity; AX, reactance area; RV, residual volume; FRC, functional residual capacity; $\mathrm{D}_{\mathrm{L}, \mathrm{co}}$, diffusion capacity of the lung for carbon monoxide; TLC, total lung capacity; VA, alveolar volume; ns, no significant difference.

Table S2 Response to SABA

\begin{tabular}{|c|c|c|c|}
\hline Parameters & Group I $($ FEV $\%<65)$ & Group $2\left(F^{2}, \%>65\right)$ & Significance \\
\hline \multicolumn{4}{|c|}{ Body plethysmography } \\
\hline$\Delta \mathrm{FEV}_{1}, \mathrm{~L}$ & $0.12(0.03$ to 0.21$)$ & $0.04(-0.05$ to 0.13$)$ & $* *$ \\
\hline$\Delta \mathrm{FEV}, \% \mathrm{p}$ & $4.0(1.1$ to 5.9$)$ & $1.4(-1.5$ to 4.4$)$ & $*$ \\
\hline$\Delta \mathrm{FVC}, \mathrm{L}$ & $0.28(0.1$ I to 0.36$)$ & 0.01 (-0.08 to 0.07$)$ & $* * *$ \\
\hline$\Delta \mathrm{FVC} \% \mathrm{p}$ & $6.8(2.7$ to 10.0$)$ & $-0.1(-2.1$ to 1.8$)$ & $* * *$ \\
\hline$\Delta \mathrm{FEV} / \mathrm{FVC}$ & $0.01(-0.02$ to 0.03$)$ & 0.01 ( -0.01 to 0.03$)$ & ns \\
\hline$\Delta \mathrm{RV}, \mathrm{L}$ & $-0.44(-0.74$ to -0.16$)$ & $-0.02(-0.19$ to 0.11$)$ & $* * *$ \\
\hline$\Delta \mathrm{RV} \% \mathrm{p}$ & $-17.8(-31.5$ to -6.4$)$ & $-1.1(-9.0$ to 4.3$)$ & $* * *$ \\
\hline$\Delta \mathrm{FRC} \% \mathrm{p}$ & $-8.5(-16.4$ to -3.1$)$ & $-2.3(-7.3$ to 2.2$)$ & $* * *$ \\
\hline$\Delta \mathrm{IC} \% \mathrm{p}$ & $6.8(0.5$ to II.7) & $-0.7(-3.8$ to 7.3$)$ & ns \\
\hline$\Delta R_{\mathrm{ex}}, \mathrm{kPa} \cdot \mathrm{s} / \mathrm{L}$ & $-1.86(-3.51$ to -0.70$)$ & $-0.37(-0.97$ to 0.13$)$ & $* *$ \\
\hline$\Delta R_{\mathrm{in}}, \mathrm{kPa} \cdot \mathrm{s} / \mathrm{L}$ & $-1.13(-1.86$ to -0.32$)$ & -0.31 ( -0.63 to -0.01$)$ & $* * *$ \\
\hline$\Delta$ Rtot\%p & $-38.8(-76.4$ to -14.9$)$ & $-12.1(-24.0$ to 0.3$)$ & $* * *$ \\
\hline \multicolumn{4}{|c|}{ Impulse oscillometry } \\
\hline$\Delta \mathrm{R} 5 \% \mathrm{p}$ & $-17.9(-43.9$ to -3.8$)$ & $-8.7(-19.9$ to -0.4$)$ & $*$ \\
\hline$\Delta R 20 \% p$ & $-10.5(-19.1$ to 2.3$)$ & $-6.7(-13.7$ to -0.5$)$ & ns \\
\hline$\Delta R 5-R 20 \% p$ & $-67.0(-156.3$ to 35.5$)$ & $-21.0(-54.3$ to 0.00$)$ & ns \\
\hline$\Delta F_{\text {res }}, \mathrm{Hz}$ & $-1.57(-3.07$ to -0.35$)$ & $-0.99(-3.73$ to 0.08$)$ & ns \\
\hline$\Delta \times 5 \% p$ & $-88.8(-209.3$ to -24.9$)$ & $-28.9(-62.2$ to -6.8$)$ & $* *$ \\
\hline$\Delta \mathrm{AX}, \mathrm{kPa} / \mathrm{L}$ & $-0.43(-0.98$ to -0.05$)$ & $-0.07(-0.28$ to -0.02$)$ & $* *$ \\
\hline \multicolumn{4}{|c|}{ Single-breath helium dilution carbon monoxide diffusion } \\
\hline$\Delta \mathrm{D}_{\mathrm{L}, \mathrm{CO}} \% \mathrm{p}$ & $3.0(1.0$ to 3.8$)$ & $1.0(-1.0$ to 3.0$)$ & $*$ \\
\hline
\end{tabular}

Notes: Bold numbers indicate significant bronchodilator response. Significant difference $(* P<0.05$, $* * P<0.0 \mathrm{I}$ and $* * * P<0.00 \mathrm{I})$ between $\mathrm{Group} \mathrm{I}$ and $\mathrm{Group} 2$. ns, no significant difference. $\triangle$ indicates absolute response.

Abbreviations: SABA, short-acting $\beta 2$ agonist (salbutamol); FEV , forced expiratory volume in I second; \%p, percent predicted; FVC, forced vital capacity; RV, residual volume; FRC, functional residual capacity; IC, inspiratory capacity; $A X$, reactance area; $\mathrm{D}_{\mathrm{L}, \mathrm{CO}}$, diffusion capacity of the lung for carbon monoxide. 
Table S3 Correlation of lung $\Delta$ function parameters after inhalation of SABA

\begin{tabular}{|c|c|c|c|c|c|c|}
\hline & $\Delta \mathrm{FEV}_{1} \% \mathrm{p}$ & $\Delta$ FVC $\%$ p & $\Delta \mathbf{R}$ tot $\%$ p & $\Delta \mathbf{R V} \% \mathbf{p}$ & $\Delta \mathbf{R 5}-\mathbf{R} 20 \%$ p & $\Delta \mathbf{A X}$ \\
\hline \multicolumn{7}{|c|}{ Correlations of $\Delta$ lung function parameters in FEV $\%$ p $<65$} \\
\hline \multicolumn{7}{|c|}{ Group I $(\mathrm{FEV}, \%<65)$} \\
\hline$\Delta \mathrm{FVC} \% \mathrm{p}$ & 0.25 & & & & & \\
\hline$\Delta$ Rtot\%p & -0.23 & $-0.64 * * *$ & & & & \\
\hline$\Delta \mathrm{RV} \% \mathrm{p}$ & 0.02 & $-0.46 *$ & $0.45^{*}$ & & & \\
\hline$\Delta R 5-R 20 \% p$ & -0.39 & -0.21 & 0.19 & -0.03 & & \\
\hline$\Delta \mathrm{AX}$ & $-0.65^{* * *}$ & $-0.49 *$ & 0.36 & 0.03 & $0.79 * * *$ & \\
\hline \multicolumn{7}{|c|}{ Correlations of $\Delta$ lung function parameters in $\mathrm{FEV}, \% \mathrm{p}>65$} \\
\hline \multicolumn{7}{|c|}{ Group $2\left(\mathrm{FEV}_{1} \%>65\right)$} \\
\hline$\Delta \mathrm{FVC} \% \mathrm{p}$ & $0.40 * *$ & & & & & \\
\hline$\Delta$ Rtot\%p & $-0.28 *$ & -0.26 & & & & \\
\hline$\Delta \mathrm{RV} \% \mathrm{p}$ & 0.08 & -0.22 & -0.10 & & & \\
\hline$\Delta R 5-R 20 \% p$ & $-0.27^{*}$ & -0.07 & 0.25 & 0.01 & & \\
\hline$\Delta \mathrm{AX}$ & $-0.42 * * *$ & -0.15 & $0.42 * *$ & -0.04 & $0.66 * * *$ & \\
\hline
\end{tabular}

Notes: $\Delta$ indicates the change in each parameter after inhaling salbutamol. Significant difference $(* P<0.05, * * P<0.01$ and $* * * P<0.00 I)$ of the correlation. Bold numbers indicate significance. Numbers presented as correlation coefficients.

Abbreviations: SABA, short-acting $\beta 2$ agonist (salbutamol); $\mathrm{FEV}_{1}$, forced expiratory volume in I second; \%p, percent predicted; FVC, forced vital capacity; RV, residual volume; $A X$, reactance area.

\section{Publish your work in this journal}

The International Journal of COPD is an international, peer-reviewed journal of therapeutics and pharmacology focusing on concise rapid reporting of clinical studies and reviews in COPD. Special focus is given to the pathophysiological processes underlying the disease, intervention programs, patient focused education, and self management protocols.

\section{Dovepress}

This journal is indexed on PubMed Central, MedLine and CAS. The manuscript management system is completely online and includes a very quick and fair peer-review system, which is all easy to use. Visit http://www.dovepress.com/testimonials.php to read real quotes from published authors. 